\title{
B.А. Мисюрин
}

\section{СТРУКТУРА И СВОЙСТВА ОСНОВНЫХ РЕЦЕПТОРОВ И ЛИГАНДОВ ВНЕШНЕГО ПУТИ АПОПТОЗА \\ ФГБНУ «РОНЦ им. Н.Н. Блохина», Москва}

\section{Контактная информация}

Всеволод Андреевич Мисюрин, к.б.н., младиий научный сотрудник лаборатории экспериментальной химиотерапии НИИ ЭДиТО

адрес: 115478 Москва, Каширское ш., 24; тел. +7(499)324-02-00

e-mail: vsevolod.misyurin@gmail.com

Статья поступила 21.04.2015, принята к печати 27.04.2015.

\section{Резюме}

Апоптоз может начаться как по внутренним причинам, так и может быть запущен извне. Передачу апоптотического сигнала внутрь клетки осуществляют несколько гомологичных друг другу рецепторов. Для активации сигнала эти рецепторы должны связаться со своими лигандами. Так, рецептор FAS связывается с FAS-лигандом, рецептор TNFR1 - с TNF $\alpha$, рецепторы TRAIL-R1 и TRAIL-R2 - с лигандом TRAIL и наконец, DR3 - с лигандом TL1A. Чаще всего, чтобы осуществить апоптоз, лиганды должны находиться в мембраносвязанной форме. Рецепторы FAS и TNFR1 запускают апоптоз только в том случае, если интернализуются в цитоплазму клетки-мишени. Eсли FAS и TNFR1 не интернализуются, то запускают антиапоптотическую программу. Рецепторы TRAIL-R1, TRAIL-R2 и DR3 не подвергаются интернализации при запуске апоптоза. Известны также рецепторы TNFR2, TRAIL-R3 и TRAIL-R4, которые активируют антиапоптотическую программу. Апоптотический сигнал начинается со сборки комплекса DISC на внутренней стороне цитоплазматической мембраны. В состав DISC обязательно входят белки FADD и прокаспаза-8, которые связываются с внутриклеточным доменом апоптотического рецептоpa. Если комплекс DISC не формируется, сигнал передаётся на NFкB-путь через каскад МАР-киназы, и запускается антиапоптотическая программа. Многообразие рецепторов и лигандов позволяет осуществлять множество функций, в том числе устранение заражённых или трансформированных клеток, начинать и завершать воспаление, модулировать процессы онтогенеза, кроветворения и выработки антител.

Ключевые слова: FAS, TNF $\alpha$, TRAIL, TL1A, апоптоз.

\section{V.A. Misyurin}

\section{STRUCTURE AND FUNCTIONS}

OF MAIN APOPTOSIS RECEPTORS AND LIGANDS

FSBSI «N.N. Blokhin Russian Cancer Research Center», Moscow

\section{Abstract}

Apoptosis can be triggered from external signals. Several homologous receptors transmit apoptotic signals from outside into the cell. For successful activation of apoptosis receptors should interact with their ligands. For example, FAS receptor must bind with FAS-ligand, TNFR1 with TNF $\alpha$, TRAIL-R1 and TRAIL-R2 with TRAIL, DR3 - with TL1A, respectively. In majority of cases ligands should be anchoring in the cell membrane to perform their functions. FAS and TNFR1 receptors trigger apoptosis only when they are internalized into the cell's cytoplasm. If FAS and TNFR1 are not internalized, then anti-apoptotic program won't start. In contrast, TRAIL-R1, TRAIL-R2 and DR3 aren't internalized during apoptotic signal transduction. Other receptors, TNFR2, TRAIL-R3 and TRAIL-R4 start an anti-apoptotic program. The apoptotic signal starts when DISC complex is formed on the inner side of the cell membrane. FADD, procaspase- 8 and intracellular domain of receptor form together DISC complex. If the DISC complex wasn't formed, signal is transmitted by the NFKB-way via MAP-kinase cascade. In such conditions anti-apoptotic program starts. A variety of receptors and ligands provides for multiple biological functions. For example, receptormediated apoptosis takes a part in elimination of infected or transformed cells, regulation of inflammation, modulation of ontogenesis, hematopoiesis and antibody production.

Key words: FAS, TNF $\alpha$, TRAIL, TL1A, apoptosis.

\section{Введение}

Рецепторы и лиганды семейства FAS - мембраносвязанные белки, экспонированные на внеш- нюю сторону клеточной мембраны. В ряде случаев эти белки находятся в растворимой форме. Первый открытый рецептор этого семейства получил название FAS. Структура остальных представителей 
во многом гомологична FAS, и функции этих белков очень сходны. Связывая свой лиганд, рецепторы передают сигнал внутрь клетки [2]. Разные рецепторы могут активировать различные регуляторные каскады. Например, при передаче сигнала от рецептора FAS активируется каспаза-3, после чего запускается необратимый апоптоз [1; 3; 11; 44]. Опосредованно каспазу-3 может также активировать и TNFR1. Но в отличие от FAS, TNFR1 имеет связи с более широким спектром сигнальных молекул. При определённых условиях TNFR1 передаёт сигнал не к каспазе-3, а стимулирует активацию сигнального пути NFкB. Передача сигнала от других рецепторов семейства FAS также имеет некоторые отличия от FAS-зависимого пути.

Каждый лиганд, представленный в данном семействе, может связываться с одним или с несколькими рецепторами, и не взаимодействует с другими. Многообразие рецепторов и лигандов семейства FAS позволяет реализовать различные программы действия. В числе этих программ есть как инициация клеточной гибели, так и преодоление апоптоза. В настоящий момент достаточно хорошо известно, при каких условиях произойдёт тот или иной ответ на стимуляцию рецепторов клеточной гибели. С другой стороны, ориентируясь на состояние тех или иных эффекторов, программу действия можно предсказать заранее. Целью данного обзора является анализ механизма работы рецепторов и лигандов клеточной гибели.

\section{Открытие}

Одним из этапов, сопровождавших открытие рецепторов и лигандов семейства FAS, были разработки хирурга-онколога Вильяма Коли, который увидел чёткую связь между перенесённой инфекцией и регрессией опухоли у больного [34]. От разработок Вильяма Коли, связанных с применением компонентов патогенных организмов для стимуляции противоопухолевого иммунного ответа, исследователи перешли к экспериментам по введению мышам вакцины БЦЖ (bacillus Calmette-Guerin) и эндотоксинов (липолисахаридов, полученных от грамотрицательных бактерий). Сыворотка крови мышей, получивших данные агенты, обладала выраженным цитотоксическим действием, что было показано на некоторых клеточных линиях. Было высказано предположение, что в лизисе трансформированных клеток участвует неизвестный компонент, выработанный иммунными клетками в ответ на проведённую стимуляцию БЦЖ и эндотоксинами. В 1984 году был выделен и описан этот компонент, названный фактором некроза опухоли (ФНО, или TNF, tumor necrosis factor, позднее - ФНО $\alpha$ и $\mathrm{TNF} \alpha$ ) [40]. Дальше, в 1989 году, две исследовательские группы независимо друг от друга получили мышиные моноклональные антитела, обладающие цитолитической активностью против различных линий клеток человека. Белок клеточной поверхности, опознаваемый этими антителами, был назван FAS и APO-1, соответственно [59; 67]. C этого момента началось исследование биологиче- ской роли рецептора FAS, функция которого известна как «рецептора клеточной смерти». Вскоре был открыт FAS-лиганд - белок, связывающийся с рецептором FAS [53]. В 1990-е гг. и чуть позже было описано множество новых белков, по своему строению очень похожих на FAS, и новых лигандов, сходных с лигандом рецептора FAS. Таким сходством обладает лиганд TRAIL, который был открыт в 1995 году при поиске белков, имеющих консервативный регион белков семейства TNF [64]. При скрининге библиотеки кДНК, экспрессируемой клетками эндотелия, в 2002 г. был обнаружен лиганд TL1A [37]. Группа лигандов, гомологичных $\mathrm{TNF} \alpha$, получила название семейство белков TNF, a их рецепторы названы соответственно TNFрецепторами.

Кроме структурного сходства эти белки обладают практически одинаковым механизмом функционирования. Очень удобно рассмотреть сначала сигнальный путь, контролируемый системой FAS-FAS-лиганд, и далее сравнить с ним сигнальные пути, ассоциированные с другими представителями семейства TNF и их рецепторов.

\section{Структура рецептора $F A S$}

\section{и FAS-лиганда и их сигнальные пути}

Рецептор FAS в некоторых литературных источниках сохранил наименование АРО-1. В современной номенклатуре дифференцировочных антигенов, или кластеров дифференцировки, этому рецептору присвоен номинал CD95. В научных статьях встречаются все три обозначения, но тексте этого обзора рецептор будет упоминаться как FAS, а его лиганд - FAS-лиганд.

В клетках человека белок FAS кодируется одноимённым геном, расположенном в локусе $10 q 24.1$ [17]. В составе гена присутствует 9 экзонов, и возможно до 18 вариантов сплайсинга мРНК гена $F A S$. Только три мРНК транслируются, формируя длинный (335 аa (аминокислотных остатков)), средний (в составе которого отсутствует трансмембранный домен), и короткий (220 аа) белок. Экспрессия гена наблюдается практически во всех клетках человеческого организма [18; 32].

Зрелый белок FAS, сформированный из полипептидной цепочки наибольшей длины, локализован в клеточной мембране. В составе полипептида выделяют N-концевой участок, формирующий внеклеточные домены, трансмембранный участок и цитоплазматический С-концевой участок, образующий после рефолдинга внутриклеточные домены. Три внеклеточных домена FAS обогащёны остатками цистеина, и названы CRD1-3 (от cysteinerich domain). За счёт заряда домена CRD2 и верхней части CRD3, FAS прочно ассоциируются с FASлигандом [50]. Домен CRD1, также известный как PLAD (pre-ligand assembly domain), не связывается c FAS-лигандом, но выполняет другие функции. Он присоединяется к CRD1 других субъединиц FAS, посредством чего три субъединицы удерживаются вместе и рецептор представляет собой гомотример [21]. В толще клеточной мембраны FAS удержива- 
ется за счёт небольшого трансмембранного домена. В цитоплазму клетки погружён так называемый «домен смерти» DD (death domain), структура которого состоит из шести антипараллельных $\alpha$ спиралей, расположенных по принципу «греческий ключ». DD предназначен для инициации апоптотического сигнала [23].

Кроме того, вблизи DD FAS имеет специальный интернализационный мотив, позволяющий клетке осуществлять интернализацию рецептора актин- и клатрин-зависимым способом [42]. Наконец, цитоплазматический конец белка имеет «домен спасения», который ингибирует цитотоксическую функцию FAS при связывании с фосфатазой FAP1 (FAS-associated phosphatase 1) [65].

Единственный известный лиганд рецептора FAS также является трансмембранным белком, но может существовать и в растворимой форме. Белок кодируется геном FASL, расположенным на хромосоме 1q23 [54]. Зрелый белок тримеризуется и в таком виде пронизывает клеточную мембрану насквозь [25]. Внеклеточный участок FAS-лиганда состоит из 179 аа и содержит консервативный домен гомологии TNF. Внеклеточный домен может расщепляться мембранными металлопротеазами -3 и -7, после чего секретируется, сохраняя при этом тримерную структуру мембранного белка [38; 45]. Интересно, что секреторная форма является очень нестабильной и в значительной степени инертной как апоптоз-индуцирующая молекула. В форме мембраносвязанного белка, экспонированного на внешней поверхности клетки, FAS-лиганд является наиболее мощным стимулятором апоптоза.

В длинном цитоплазматическом домене FAS-лиганда имеется несколько мотивов, предназначенных для взаимодействия с транспортными молекулами, и участок фосфорилирования [13].

Инициация проведения апоптотического сигнала осуществляется при связывании мембранной формы FAS-лиганда c FAS, расположенным на мембране другой клетки. Согласно большинству авторов, как FAS-лиганд, так и FAS представляют собой тримеры [50], однако есть данные, что при инициации апоптоза FAS формирует структуру из 5 и даже 7 субъединиц [62].

В любом случае, домен DD рецептора FAS связывается с цитоплазматическим белком FADD (FAS-распознающий белок с «доменом смерти», от FAS-associated protein with death domain). В структуре самого FADD имеется как домен DD, так и домен DED (death effector domain), который позволяет FADD ассоциироваться с каспазой-8 [43]. Связанные между собой белки FAS/FADD/каспаза-8 называют также комплексом DISC (death-inducing signaling complex) [28].

После сборки DISC на внутриклеточной стороне клеточной мембраны возможно два пути развития событий. В клетках типа I (например - лимфоидные клетки) ассоциация FAS и FAS-лиганда со сборкой DISC сопровождается интернализацией, или эндоцитозом рецептора со всеми связанными факторами [42].
После интернализации комплекс DISC очень быстро проводит циклы расщепления прокаспазы8. В результате в цитоплазму высвобождается очень много молекул активной каспазы- 8 в виде гетеротетрамеров из двух малых (p10) и двух больших (p20) субъединиц. Каспаза-8 взаимодействует с прокаспазой-3, конвертируя её в активную каспазу-3. Каспаза-3 сразу же начинает расщеплять различные белковые субстраты, в том числе ферменты репарации ДНК, цитоплазматические и ядерные структурные белки, белки веретена деления и эндонуклеазы [47]. Более того, каспаза-3 активирует прокаспазы -6 и -7, которые ускоряют осуществление апоптоза [49].

В клетках типа II (гепатоциты) сборка DISC и последующая активация прокаспазы-8 затруднена регуляторными молекулами FAP1, c-FLIP (FLICElike-inhibitory-protein) и PED-PEA15 [18; 24; 48]. Из-за наличия регуляторов, в цитоплазме клеток типа II формируется небольшое число молекул каспазы-8, которых не достаточно для запуска апоптоза по пути, характерному для клеток типа I. Основной эффект достигается за счёт фактора $\mathrm{tBID}$, который образуется при расщеплении каспазой-8 белка BID. tBID стимулирует встраивание белка BAX в митохондриальную мембрану, через которую освобождается цитохром C $[4 ; 66]$. В цитоплазме из Apaf-1 (apoptosis protease-activating factor), прокаспазы-9 и цитохрома С, формируется апоптосома, которая освобождает каспазу-9. Осуществлению апоптоза может препятствовать фактор XIAP (Xlinked inhibitor of apoptosis protein), однако вместе с цитохромом С из митохондрии освобождается SMAC (second mitochondria-derived activator of caspases), ингибирующий ХІАР. Если работа ХІАР связана молекулой SMAC, то каспаза-9 успешно активирует прокаспазу-3, и, как было сказано выше, апоптоз уже необратим.

Белок FADD - не единственный активатор FAS-индуцируемого апоптоза. FAS взаимодействует с другим белком - RIP1 (receptor interacting protein 1), в структуре которого, также, как и в структуре FADD, найден DD. Комплекс FAS-RIP1 привлекает белок RAIDD (RIP-associated ICH1/CED-3-homologous protein with a DD) и прокаспа3y-2 [27].

Во многих типах клеток рецептором FAS также активируется киназа JNK (c-Jun N-terminal kinase) [39]. Сигнальный путь от FAS до JNK имеет следующих посредников: Daxx (Death Domain associated protein), Ask1 и MKK5. Активная JNK противодействует NFкB-зависимой экспрессии антиапоптотических белков, в том числе XIAP, что способствует осуществлению апоптоза [55]. Кроме того, JNK способствует протеосомной деградации белка c-FLIP, который, как было указано выше, блокирует активацию прокаспазы-8. Описан и антиапопточеский сигнальный путь, индуцированный системой FAS-FAS-лиганд. В случае если интернализация рецептора не происходит, сборка комплекca DISC осуществляется очень медленно, и активирующий сигнал получают каскад MAPK и NFкB- 
путь. Эти эффекторы способствуют выживанию клетки. Следует отметить, что активация МАРК и NFкB рецептором FAS происходит и при его интернализации, однако их антиапоптотический эффект в таких условиях незначителен [16].

\section{Cтруктура TNFR1, TNFR2}

\section{и TNFa, и их сигнальные пути}

Ген TNFRSF1A расположен на хромосоме 12 p13.31 и кодирует белок, состоящий из 455 аа [19]. Структура рецептора очень похожа на FAS, однако во внеклеточном домене локализованы не три, а четыре CRD. Подобно FAS, TNFR1 тримеризуется за счёт CRD1, а со своим лигандом связывается при помощи участков CRD2 и CRD3 [60]. Во внутриклеточном домене TNFR1, непосредственно под плазматической мембраной, расположен мотив для сборки комплекса на клеточной мембране [51].

Имеется мотив DD, позволяющий формировать комплекс DISC. Кроме этого, TNFR1 имеет мотив для связывания адаптерного белка FAN (factor associated with neutral sphingomyelinase activation), который в дальнейшем связывается и активирует NSMase (membrane-bound neutral sphingomyelinase) [9].

Рецептор TNFR2 кодируется геном TNFRSF1B, локализованным в хромосоме 1p36.22. Зрелый белок состоит из 461 аa. Он структурно сходен с TNFR1 и FAS, однако не имеет DD в трансмембранном домене и не связывается с DDсодержащими адаптерами [10].

Ген TNF $\alpha$ расположен на хромосоме 6р21.3. Длина полипептидной цепи составляет 233 аа. Подобно FAS-лиганду, TNF $\alpha$ содержит консервативный домен гомологии TNF. TNF $\alpha$ в основном существует в форме гомотримерного трансмембранного белка [56]. Под действием ТАCE (TNF $\alpha-$ converting enzyme) мембраносвязанный TNF $\alpha$ pacщепляется и секретируется [12]. Секреторная форма стабильна и способна индуцировать апоптоз, что не характерно для родственного ему FAS-лиганда. TNF $\alpha$ практически с одинаковым сродством распознаётся как TNFR1, так и TNFR2.

Подобно системе FAS-FAS-лиганд, TNFR1 при ассоциации с TNF $\alpha$ способен запускать апоптотический сигнальный путь. Принципиальных отличий между FAS- и TNFR1-опосредованной активации апоптоза нет, за исключением того, что в состав DISC при TNFR1 входит фактор TRADD (TNFR-associated death domain) [51]. При интернализации TNFR1 комплекс DISC формируется с наибольшей интенсивностью. Однако в физиологических условиях наиболее часто интернализация не происходит, а TNFR1 стимулирует провоспалительные эффекты. В течение нескольких минут после связывания TNFR1 с TNF $\alpha$ к цитоплазматическому домену TNFR1 присоединяются белки RIP1, TRAF2 (TNF receptor-associated factor 2) и сIAP1/2 (inhibitor of apoptosis protein 1/2), образуя комплекс I [36]. В составе комплекса I белки подвергаются модификации. В частности, происходит убиквитинирование RIP1. Убиквитинированный RIP1 при- влекает TAK1 (transforming growth factor- $\beta$-activated kinase 1) и IKK (Inhibitor of nuclear factor $\kappa$-B kinase) в комплекс I, что приводит к активации сигнального пути NFкB [20; 31]. С другой стороны, взаимодействие TRAF2-RIP1 индуцирует передачу сигнала по MEKK1-каскаду (MAPK/ERK kinase 1) к киназе JNK, которая способствует каспазо-8зависимому апоптозу. Активация апоптоза происходит в основном тогда, когда сигнальные пути, контролирующие TNFR1-опосредованное выживание клетки, не активны.

Авидность связи мембранного TNF $\alpha$ с TNFR2 выше, чем у растворимой формы TNF $\alpha$. При ассоциации этих беков цитоплазматический домен TNFR2 связывается с TRAF2. Как в случае с TNFR1, комплекс TNFR2-TRAF2 активирует cIAP1/2 [46]. В физиологических условиях сигнал передаётся к промоторам гена AP-1 (activator protein 1), который запускает антиапоптотическую программу, и незначительно активируется NFкB [26]. В случае гиперэкспрессии TNFR2 активность NFкB также возрастает, но несопоставимо меньше, чем при стимуляции TNFR1.

\section{Cтруктура TRAIL,}

его рецепторов, и их сигнальные пути

Ген, кодирующий TRAIL, расположен на хромосоме 3q26. Как мембранно-связанная, так и растворимая форма белка вызывают апоптоз.

Известно пять рецепторов, с которыми может связываться TRAIL. Два рецептора активируют апоптотический сигнал - это TRAIL-рецептор-1 (TRAIL-R1, DR4 или TNFRSF10A) и TRAIL-R2 (DR5 или TNFRSF10B). Три других рецептора, TRAIL-R3 (DcR1), TRAIL-R4 (DcR2) и OPG (от osteoprotegerin), связывают TRAIL, но не передают апоптотический сигнал, так как не имеют цитоплазматического домена вообще (TRAIL-R3), либо имеют дефектный DD-мотив (TRAIL-R4), либо связываются с низкой (OPG) аффинностью [30]. Гены TRAIL-R1 и TRAIL-R2 расположены в локусе $8 \mathrm{p} 21.3$, и кодируют очень сходные структурно и функционально рецепторы. Внеклеточные домены обоих белков имеют мотивы CRD, типичные для рецепторов семейства FAS $[41 ; 61]$. Внутриклеточные домены TRAIL-R1 и TRAIL-R2 имеют мотивы $\mathrm{DD}$. мРНК всех пяти рецепторов экспрессируется в клетках человека, однако её количество в основном не коррелирует количеством молекул рецепторов на плазматической мембране [22].

При связывании с TRAIL рецепторы TRAILR1 и TRAIL-R2 передают как апоптотический, так и антиапоптотические сигналы. При передаче апоптотического сигнала TRAIL-R1 и TRAIL-R2 формируют комплекс DISC. В отличие от FAS и TNFR1, эти рецепторы не интернализуются, и конвертируют значительное число молекул прокаспазы-8, не покидая плазматическую мембрану [29]. Рецептор TRAIL-R4 передаёт только антиапоптотический сигнал, a TRAIL-R3 не передаёт никакого сигнала. Пока неизвестно, что происходит при связывании OPG и TRAIL. 
Структура и сигнальные пути TL1A и DR3

Рецептор DR3 (также известный, как Аро-3, LARD и TRAMP) был открыт при исследовании свойств белков, имеющих DD-мотив [14; 33]. Ген расположен в локусе 1p36.2, имеет 9 экзонов [52]. За счёт альтернативного сплайсинга возможно образование 11 форм белка DR3, среди которых есть и секреторные. Мембраносвязанная форма DR3 образуется из полипептидной цепи длиной 417 aa. Внеклеточный домен имеет четыре мотива CRD. Подобно другим рецептором семейства FAS, DR3 тримеризуется в плазматической мембране. Мотивы CRD2 и CRD3 осуществляют связь DR3 с его единственным лигандом TL1A.

TL1A в своей структуре не имеет принципиальных отличий от других лигандов семейства TNF. Его ген расположен на хромосоме 9p32 [37].

Система TL1A-DR3 контролирует как апоптотические, так и антиапоптотические сигнальные пути. Инициация апоптоза проходит с формированием комплекса FADD-TRADD-TRAF2-прокаспазы8 на мембране и последующей активацией каспазы-3 в цитоплазме клетки. Антиапоптотический сигнальный путь запускается при связывании цитоплазматическим доменом DR3 белков TRADD, TRAF2, RIP1. FADD и прокаспаза-8 в комплекс в данном пути не участвуют [63]. Нижестоящими эффекторами являются ERK, JNK и NFкB, причём инактивация NFкB является обязательным условием индукции DR3-зависимого апоптоза [35].

\section{Физиологическая}

\section{и патофизиологическая роль}

Осуществление апоптоза очень важно при развитии человеческого организма. Так, в процессе формирования нервной и иммунной системы происходит значительное перепроизводство клеток. В приведённых системах апоптоз позволяет устранить клетки, не сформировавшие функциональные синаптические связи или не сумевшие произвести высокоаффинный антиген-специфичный рецептор, соответственно. Аутореактивные лимфоциты получают апоптотический сигнал и быстро обезвреживаются. Кроме того, посредством апоптоза в организме устраняются клетки, поражённые патогенами, он способствует заживлению ран при устранении иммунных клеток.

В организме взрослого человека имеется несколько иммунопривелегированных зон, в которые посредством проапоптотических сигналов не допускаются клетки иммунной системы. Наконец, взаимодействие апоптотический рецептор-лиганд играет роль в противоопухолевом иммунном надзоре $[10 ; 15 ; 30]$. Строгий надзор возможен по той причине, что все (за некоторыми исключениями) клетки человека имеют на своей поверхности апоптотические рецепторы, однако комплиментарные им лиганды экспрессируются либо секретируются иммунными клетками. В случае дисбаланса в системах регуляции экспрессии апоптотических рецепторов и лигандов происходят различные дегенеративные процессы [5-8].
FAS экспрессируется на поверхности практически всех клеток человека, за исключением активированных Т-цитотоксических лимфоцитов и NK-клеток, а также клеток иммунопривелегированных зон [32]. FAS-лиганд экспрессируется иммунными клетками при принятии решения о ликвидации заражённой или опухолевой клетки.

При успешном запуске апоптотической гибели клетки, экспрессия FAS-лиганда Tлимфоцитом прекращается, чтобы не разрушить соседние клетки. Если FAS-лиганд экспрессируется неиммунными клетками (например, клетками Сертоли в семенных канальцах), то его синтез происходит постоянно. Это допустимо, так как окружающие клетки нечувствительны к FAS-FASлиганд опосредованному апоптозу, а клетки иммунитета никогда не допускаются туда.

Основная роль TNF $\alpha$ заключается в регуляции активности клеток иммунной системе при непосредственном участии в противоопухолевом и противоинфекционном иммунном ответе [10]. Активированные макрофаги, нейтрофилы, тучные клетки, натуральные киллеры, эозинофилы и CD4+ лимфоциты ответственны за выработку этого цитокина в ответ на сигналы в начале воспаления. Связываясь с TNFR1 и TNFR2 иммунных клеток, TNF $\alpha$ активирует транскрипцию генов, ответственных, прежде всего, за острую фазу воспаления. Этот цитокин стимулирует пролиферацию и созревание клонов, эффективно распознавших презентированные антигены. По окончании иммунного ответа, TNF $\alpha$ активирует апоптоз иммунных клеток в очаге воспаления, чтобы прекратить их разрушительное воздействие на близлежащие ткани. TNFR1 экспрессируется всеми без исключения клетками лимфоидной системы и практически всеми остальными клетками человека.

TNFR2 в основном присутствует на поверхности клеток центральной нервной системы и иммунных клеток, таких как CD4+ и CD9+ лимфоциты [57; 58]. Обычно TNFR2 коэкспрессируется с TNFR1. Поскольку TNFR1 и TNFR2 при связывании с TNF $\alpha$ активируют разные сигнальные пути, преобладание одного из них на поверхности клетки определяет ответ на стимуляцию. Так, доминирование TNFR2 позволяет клетке выживать. При избыточной продукции TNF $\alpha$ оказывает цитотоксическое воздействие на все клетки организма. Это выражается в виде развития болезни Альцгеймера, сердечной недостаточности, и многих других заболеваний, непосредственно связанных с истощением клеточного пула внутри ткани [15].

TRAIL конститутивно экспрессируется во многих тканях человека в контексте мРНК. В виде белка TRAIL экспрессируется преимущественно клетками иммунной системы, в особенности натуральными киллерами, Т-цитотоксическими лимфоцитами, дендритными клетками и макрофагами. Находясь в состоянии покоя, иммунные клетки сохраняют молекулы TRAIL в цитоплазме [30].

Рецептор TRAIL-R1 экспрессируется в клетках большинства тканей человеческого организма, 
включая селезёнку, тимус, печень, а также в лейкоцитах периферической крови, активированных Тлимфоцитах и клетках тонкого кишечника. Экспрессия TRAIL-R2 обнаруживается во всех типах клеток нормальных тканей, а также во всех опухолевых клеточных линиях; выше всего уровни его экспрессии в клетках селезёнки, лейкоцитах периферической крови и активированных лимфоцитах. Основной эффект, достигаемый работой системы TRAIL-рецепторы TRAIL, это осуществление противоопухолевого и противовирусного иммунного надзора цитотоксическими клетками. Т-клетки, в ответ на их стимуляцию через молекулу CD59, секретируют микровезикулы, мембраны которых обогащены молекулами TRAIL [30].

Экспрессия TLA1 в основном наблюдается в эндотелиальных клетках пупочной вены и синовинальных клетках, клетках желудочно-кишечного тракта. В ответ стимуляцию такими цитокинами, как TNF $\alpha$ и IL-1 T-клетки различных популяций также экспрессируют TLA1. В остальных клетках человека ген TLA1 неактивен.

Рецептор DR3 экспрессируется у практически всех клеток иммунной системы. TL1A-DR3 в основном управляет взаимодействием эффекторных и регуляторных Т-клеток с другими иммунными клетками, а также играет роль в аллергических реакциях, происходящих на слизистых оболочках лёгких и желудочно-кишечного тракта.
Гиперэкспрессия TL1A провоцирует развитие аутоиммунных заболеваний, прежде всего тяжёлых форм ревматоидного артрита и болезни Крона [35].

\section{Заключение}

Самым простым и действенным способом осуществления апоптоза является контакт между NK или Т-цитотоксической клеткой, имеющей FAS-лиганд, и клеткой-мишенью, обладающей FAS и системой, позволяющей осуществить его интернализацию.

Апоптоз, запущенный в трансформированной или заражённой вирусом клетке, не приводит к разрушению других клеток или выбросу ядовитых веществ во внутреннюю среду организма. Однако множество тканей в организме находятся в так называемом квазистационароном состоянии, и клетки этих тканей после катастрофических событий не восстанавливаются до своего исходного числа. Таким образом, просто необходимо наличие систем, способных ограничивать развитие FASопосредованного апоптоза.

Вероятно, именно этой причине развилось несколько систем рецепторов и лигандов. Их многообразие открывает возможность осуществлять либо клеточную гибель, либо продолжать проведение защитных реакций, модулировать процессы кроветворения и секреции антител.

\section{Литература}

1. Барышников А.Ю. Программируемая клеточная смерть (апоптоз) // Клиническая онкогематология. Фундаментальные исследования и клиническая практика. - 2001. - С. 36.

2. Барышников А.Ю., Шишкин Ю.В. FAS/APO-1 антиген - молекула, опосредующая апоптоз // Гематология и трансфузиология. - 1995. - № 6. - С. 35.

3. Барышников А.Ю., Шишкин Ю.В. Программированная клеточная смерть (апоптоз) // Российский онкологический журнал. - 1996. - № 1. - С. 58.

4. Карапетян В.Л., Степанова Е.В., Барышников А.Ю., Никогосян С.О., Кузнецов В.В. Экспрессия маркеров апоптоза (P53, BCL-2, BAX) и их прогностическое значение при эпителиальных новообразованиях яичников ранних стадий // Российский биотерапевтический журнал. - 2011. - Т. 10, № 2. - С. 45-9.

5. Короленкова Л.И., Степанова Е.В., Барышников А.Ю. Молекулярно-биологические маркеры пролиферации и апоптоза, как факторы прогрессии цервикальных интраэпителиальных неоплазий и рака шейки матки // Российский биотерапевтический журнал. - 2010. - Т. 9, № 4. - С. 11-6.

6. Кохно А.В., Савченко В.Г., Паровичникова Е.Н. и др. Апоптоз и пролиферативная активность клеток костного мозга у больных апластическими синдромами по данным трепанобиопсии // Терапевтический архив. - 2001. № 7. - C. 51 .

7. Тагиров О.Т., Кравченко Г.А., Козлов А.Ю. и др. Растворимый FAS(CD95) белок, ингибирующий апоптоз как прогностический биомаркер течения рака молочной железы // Вестник Нижегородского университета им. Н.И. Лобачевского. Серия: Биология. - 2001. - № 1. С. - 21-5.

8. Уткин О.В., Сахарнов Н.А., Преснякова Н.Б. и др. Экспрессия CD95/Fas в клетках крови при раке толстой кишки // Российский биотерапевтический журнал. - 2013. - Т. 12, № 1. - С. $23-9$.

9. Adam D., Wiegmann K., Adam-Klages S. et al. A novel cytoplasmic domain of the p55 tumor necrosis factor receptor initiates the neutral sphingomyelinase pathway // J. Biol. Chem. - 1996. - 271. - P. 14617-22.

10. Aggarwal B.B. Signalling pathways of the TNF superfamily: a double-edged sword // Nature Reviews Immunology. 2003. - 3(9). - P. 745-56.

11. Baryshnikov A.Y., Zabotina T.N., Sedyakhina N.P. et al. The coexpression of cd34-antigen of early hemopoietic precursors and FAS/APO-1 (CD95)-antigen mediating apoptosis // Experimental Oncology. - 1994. - 16. - P. 343.

12. Black R.A., Rauch C.T., Kozlosky C.J. et al. A metalloproteinase disintegrin that releases tumour-necrosis factor-alpha from cells // Nature. - 1997. - 385. - P. 729-33.

13. Blott E.J., Bossi G., Clark R. et al. Fas ligand is targeted to secretory lysosomes via a proline-rich domain in its cytoplasmic tail // J. Cell Sci. - 2001. - 114. - P. 2405-16.

14. Bodmer J.L., Burns K., Schneider P. et al. TRAMP, a novel apoptosis-mediating receptor with sequence homology to tumor necrosis factor receptor 1 and Fas(Apo-1/CD95) // Immunity. - 1997. - 6. - P. 79-88. 
15. Bradley J.R. TNF-mediated inflammatory disease // J Pathol. - 2008. - 214(2). - P. 149-60.

16. Chakrabandhu K., Huault S., Garmy N. et al. The extracellular glycosphingolipid-binding motif of Fas defines its internalization route, mode and outcome of signals upon activation by ligand // Cell Death Differ. - 2008. - 15. - P. 182437.

17. Cheng J., Liu C., Koopman W.J., Mountz J.D. Characterization of human Fas gene. Exon/intron organization and promoter region // J. Immunol. - 1995. - 154. - P. 1239-45.

18. Condorelli G., Vigliotta G., Cafieri A. PED/PEA-15: an anti-apoptotic molecule that regulates FAS/TNFR1-induced apoptosis // Oncogene. - 1999. - 18(31). - P. 4409-15.

19. Dembic Z., Loetscher H., Gubler U. et al Two human TNF receptors have similar extracellular, but distinct intracellular, domain sequences // Cytokine. - 1990. - 2. - P. 231-7.

20. Ea C.K., Deng L., Xia Z.P., Pineda G., Chen Z.J. Activation of IKK by TNFalpha requires site-specific ubiquitination of RIP1 and polyubiquitin binding by NEMO // Mol. Cell. - 2006. - 22. - P. 245-57.

21. Edmond V., Dufour F., Poiroux G. et al. Downregulation of ceramide synthase-6 during epithelial-to-mesenchymal transition reduces plasma membrane fluidity and cancer cell motility // Oncogene. - 2014 doi: 10.1038/onc.2014.55. [Epub ahead of print]

22. Falschlehner C., Ganten T.M., Koschny R. et al. TRAIL and other TRAIL receptor agonists as novel cancer therapeutics // Adv. Exp. Med. Biol. - 2009. - 647. - P. 195-206.

23. Huang B., Eberstadt M., Olejniczak E.T. NMR structure and mutagenesis of the Fas (APO-1/CD95) death domain // Nature. $-1996 .-384(6610)$. - P. 638-41.

24. Irmler M., Thome M., Hahne M. Inhibition of death receptor signals by cellular FLIP // Nature. - 1997. - 388(6638). P. $190-5$.

25. Janssen O., Qian J., Linkermann A., Kabelitz D. CD95 ligand - Death factor and costimulatory molecule? // Cell Death Differ. - 2003. - 10. - P. 1215-25.

26. Ji W., Li Y., Wan T. et al. Both internalization and AIP1 association are required for tumor necrosis factor receptor 2mediated JNK signaling // Arteriosclerosis, Thrombosis, and Vascular Biology. - 2012. - 32(9). - P. 2271-9.

27. Kelliher M.A., Grimm S., Ishida Y. The death domain kinase RIP mediates the TNF-induced NF-kappaB signal // Immunity. - 1998. - 8(3). - P. 297-303.

28. Kischkel F.C., Hellbardt S., Behrmann I. Cytotoxicity-dependent APO-1 (Fas/CD95)-associated proteins form a deathinducing signaling complex (DISC) with the receptor // EMBO J. - 1995. - 14(22). - P. 5579-88.

29. Kohlhaas S.L., Craxton A., Sun X.M. et al. Receptor-mediated endocytosis is not required for tumor necrosis factorrelated apoptosis-inducing ligand (TRAIL)-induced apoptosis // J. Biol. Chem. - 2007. - 282. - P. 12831-41.

30. LeBlanc H.N., Ashkenazi A. Apo2L/TRAIL and its death and decoy receptors // Cell Death Differ. - 2003. - 10(1). - P. 66-75.

31. Li H., Kobayashi M., Blonska M., You Y., Lin X. Ubiquitination of RIP is required for tumor necrosis factor alphainduced NF-kappaB activation // J. Biol. Chem. - 2006. - 281. - P. 13636-43.

32. Malleter M., Tauzin S., Bessede A. CD95L cell surface cleavage triggers a prometastatic signaling pathway in triplenegative breast cancer // Cancer Res. - 2013. - 73(22). - P. 6711-21.

33. Marsters S.A., Sheridan J.P., Donahue C.J. et al. Apo-3, a new member of the tumor necrosis factor receptor family, contains a death domain and activates apoptosis and NF-kappa B // Curr. Biol. - 1996. - 6. - P. 1669-76.

34. McCarthy E.F. The Toxins of William B. Coley and the Treatment of Bone and Soft-Tissue Sarcomas // Iowa Orthop J. -2006. - 26. - P. 154-8.

35. Meylan F., Richard A.C., Siegel R.M. TL1A and DR3, a TNF family ligand-receptor pair that promotes lymphocyte costimulation, mucosal hyperplasia, and autoimmune inflammation // Immunol Rev. - 2011. - 244(1). - P. $188-96$.

36. Micheau O., Tschopp J. Induction of TNF receptor I-mediated apoptosis via two sequential signaling complexes. Cell. 2003. - 114. - P. 181-90.

37. Migone T.S., Zhang J., Luo X. et al. TL1A is a TNF-like ligand for DR3 and TR6/DcR3 and functions as a T cell costimulator // Immunity. - 2002. - 16. - P. 479-92.

38. Mitsiades N., Yu W.H., Poulaki V. et al. Matrix metalloproteinase-7-mediated cleavage of Fas ligand protects tumor cells from chemotherapeutic drug cytotoxicity // Cancer Res. - 2001. - 61. - P. 577-81.

39. Moreno E., Yan M., Basler K. Evolution of TNF signaling mechanisms: JNK-dependent apoptosis triggered by Eiger, the Drosophila homolog of the TNF superfamily // Curr Biol. - 2002. - 12(14). - P. 1263-8.

40. Old L.J. Tumor necrosis factor (TNF) // Science. - 1985. - 230(4726). - P. 630-2.

41. Pan G., O'Rourke K., Chinnaiyan A.M. et al. The receptor for the cytotoxic ligand TRAIL // Science. - 1997. - 276. P. 111-3.

42. Parlato S., Giammarioli A.M., Logozzi M. et al. CD95 (APO-1/Fas) linkage to the actin cytoskeleton through ezrin in human T lymphocytes: A novel regulatory mechanism of the CD95 apoptotic pathway // EMBO J. $-2000 .-19$. - P. 5123-34.

43. Peter M.E., Krammer P.H. The CD95(APO-1/Fas) DISC and beyond // Cell Death Differ. - 2003. - 10. - P. $26-35$.

44. Polosukhina E.R., Baryshnikov A.Yu., Shishkin Yu.V. et al. Expression of antigen CD95(FAS/APO-1) mediating apoptosis in hemoblastoses using monoclonal antibodies ICO-160 // Гематология и трансфузиология. - 2000. - 45(4). - P. 3-6.

45. Ptisyna Y.S., Bornyakova L.A., Baryshnikov A.Y. et al. A soluble form of FAS/APO-1 (CD95) antigen in the serum of viral hepatitis patients // International Journal on Immunorehabilitation. - 1999. - 14. - P. 110.

46. Rothe M., Sarma V., Dixit V.M., Goeddel D.V. TRAF2-Mediated activation of NFkB by TNF receptor 2 and CD40// Science. - 1995. - 269(5229). - P. 1424-7.

47. Sakahira H., Enari M., Nagata S. Cleavage of CAD inhibitor in CAD activation and DNA degradation during apoptosis // Nature. - 1998. - 391(6662). - P. 96-9.

48. Sato T., Irie S., Kitada S., Reed J.C. FAP-1: a protein tyrosine phosphatase that associates with Fas // Science. - 1995. 268(5209). - P. 411-5. 
49. Scaffidi C., Fulda S., Srinivasan A. Two CD95 (APO-1/Fas) signaling pathways // EMBO J. - 1998. - 17(6). - P. 167587.

50. Schneider P., Bodmer J.L., Holler N. et al. Characterization of Fas (Apo-1, CD95)-Fas ligand interaction // J Biol Chem. - 1997. - 272(30). - P. 18827-33.

51. Schneider-Brachert W., Tchikov V., Neumeyer J. et al. Compartmentalization of TNF receptor 1 signaling: Internalized TNF receptosomes as death signaling vesicles // Immunity. - 2004. - 21. - P. 415-28.

52. Screaton G.R., Xu X.N., Olsen A.L. et al. LARD: A new lymphoid-specific death domain containing receptor regulated by alternative pre-mRNA splicing // Proc. Natl. Acad. Sci. USA. - 1997. - 94. - P. 4615-9.

53. Suda T., Takahashi T., Golstein P., Nagata S. Molecular cloning and expression of the Fas ligand, a novel member of the tumor necrosis factor family // Cell. - 1993. - 75(6). - P. 1169-78.

54. Takahashi T., Tanaka M., Inazawa J. et al. Human Fas ligand: Gene structure, chromosomal location and species specificity // Int. Immunol. - 1994. - 6. - P. 1567-74.

55. Tang G., Minemoto Y., Dibling B. et al. Inhibition of JNK activation through NF-kappaB target genes // Nature. -2001. -414. - P. 313-7.

56. Tang P., Hung M.C., Klostergaard J. Human pro-tumor necrosis factor is a homotrimer // Biochemistry. - 1996. - 35. P. 8216-25.

57. Tartaglia L.A., Goeddel D.V., Reynolds C. et al. Stimulation of human T-cell proliferation by specific activation of the 75-kDa tumor necrosis factor receptor // Journal of Immunology. - 1993. - 151(9). - P. 4637-41.

58. Tartaglia L.A., Weber R.F., Figari I.S. et al. The two different receptors for tumor necrosis factor mediate distinct cellular responses // Proceedings of the National Academy of Sciences of the United States of America. - 1991. - 88(20). P. 9292-6.

59. Trauth B.C., Klas C., Peters A.M. et al. Monoclonal antibody-mediated tumor regression by induction of apoptosis // Science. - 1989. - 245(4915). - P. 301-5.

60. Wajant H., Pfizenmaier K., Scheurich P. Tumor necrosis factor signaling // Cell Death Differ. - 2003. - 10. - P. 45-65.

61. Walczak H., Degli-Esposti M.A., Johnson R.S. et al. TRAIL-R2: A novel apoptosis-mediating receptor for TRAIL // EMBO J. - 1997. - 16. - P. 5386-97.

62. Wang L., Yang J.K., Kabaleeswaran V. et al. The Fas-FADD death domain complex structure reveals the basis of DISC assembly and disease mutations // Nat Struct Mol Biol. - 2010. - 17(11). - P. 1324-9.

63. Wen L., Zhuang L., Luo X., Wei P. TL1A-induced NF-kappaB activation and c-IAP2 production prevent DR3-mediated apoptosis in TF-1 cells // J. Biol. Chem. - 2003. - 278. - P. 39251-8.

64. Wiley S.R., Schooley K., Smolak P.J. et al. Identification and characterization of a new member of the TNF family that induces apoptosis // Immunity. - 1995. - 3. - P. 673-82.

65. Yanagisawa J., Takahashi M., Kanki H. The molecular interaction of Fas and FAP-1. A tripeptide blocker of human Fas interaction with FAP-1 promotes Fas-induced apoptosis // J Biol Chem. - 1997. - 272(13). - P. 8539-45.

66. Yin X.M. Signal transduction mediated by Bid, a pro-death Bcl-2 family proteins, connects the death receptor and mitochondria apoptosis pathways // Cell Res. - 2000. - 10(3). - P. 161-7.

67. Yonehara S., Ishii A., Yonehara M. A cell-killing monoclonal antibody (anti-Fas) to a cell surface antigen codownregulated with the receptor of tumor necrosis factor // J Exp Med. - 1989. - 169(5). - P. 1747-56. 